\title{
Proposta de Identificação de Manifestações de Aprendizagens em AVA através da Aplicação de Parâmetros
}

\author{
Ederclinger Melo Reis ${ }^{1}$, Francisco Herbert Lima Vasconcelos ${ }^{1}$, Cibelle Amorim \\ Mrtins ${ }^{1}$, Ana Paula de Oliveira Ximenes ${ }^{1}$ \\ ${ }^{1}$ Departamento Instituto Universidade Virtual - Instituto UFC Virtual - Universidade \\ Federal do Ceará (UFC) \\ Av. Humberto Monte, s/n, Campus do Pici, Bloco 901 (1ª Andar) - 60440-554 - \\ Fortaleza - Ceará - Brazil \\ ederclingerdyahoo.com.br, \{herbert, cibelle.amorim, \\ anaximenes\} @virtual.ufc.br
}

\begin{abstract}
This paper proposes to identify learning through parameters in order to foster moments of an education network through discourse analysis through observation of parameters, where the intention is to describe the related the subtended by acting as observers in the field investigated.
\end{abstract}

Resumo. Este artigo propõe identificar de aprendizagens através de parâmetros com vistas a favorecer momentos de uma rede de educação por meio de análise do discurso, onde a intenção é descrever o relacionado os subtendidos, agindo como observadores no campo investigado.

\section{Introdução}

O tema 'identificação de aprendizagem por meio de parâmetros em ferramentas de interação na Educação a Distância $(\mathrm{EaD})$ ' é a abordagem que tem a sua origem no constante avanço das Tecnologias Digitais de Informação e Comunicação (TDIC).

Além das TDIC, nossa pesquisa introduz o reconhecimento de ciberespaço, que segundo Lévy (1999), é composto de "infraestrutura material de comunicação digital, mas também o universo oceânico de informações que ela abriga, assim como os seres humanos que navegam e alimentam esse universo." [LÉVY, 1999, p. 17].

Questionamo-nos como as aprendizagens se manifestam no Ambiente Virtual de Aprendizagem (AVA) representando partes inerentes e significativas do processo de construção do conhecimento. Também ainda há muitas lacunas $\mathrm{EaD}$ com aplicabilidade de diretrizes para análises por meio de parâmetros com vistas à identificação da ação educativa e formativa.

Diante destes contextos, nosso objetivo é identificar aprendizagens por meio de parâmetros com vistas a favorecer momentos de uma educação em rede. Para tanto, se pretende delimitar categorias com base nos aspectos de diálogos e interações na EAD, validar os parâmetros através das suas aplicações em ferramentas de interação em AVA e propor novas formas de análises de discurso de textos expressos pelos atores na construção do conhecimento. 


\section{Diálogo e as trocas relacionadas à Educação a Distância}

A interação em EaD demonstra a possibilidade de resolver o problema da distância entre os atores do conhecimento através do diálogo medido [Moore 1993 e Peters 2003]. Dentro de uma perspectiva ideológica e política, o diálogo é um fator de libertação [Freire 2006]. Por outro lado, a função do mediador é fundamental para o sujeito buscar sua autonomia e se apropriar do conhecimento, de acordo com a realidade do aluno e da educação.

No viés construtivista-interacionista de Piaget [1983], o aprendizado deve ser individual e coletivo, por meio do qual o conhecimento é resultado da interação dos sujeitos com o seu entorno. Dessa forma há uma construção individual e a ação é o instrumento de troca [Piaget 1983].

\section{Tipo de Pesquisa}

O tipo de pesquisa que colocamos em prática é análise do discurso por meio da observação de parâmetros, em que a intenção está relacionada a descrever os subtendidos por meio da atuação como observadores no campo investigado. Na pesquisa da análise do discurso, o investigador tem o papel de não interferir no grupo, mas a investigação e os investigados podem ser os que têm a maior reação na tentativa de solucionar problemas propostos já que após as publicações, os mesmos podem redirecionar posicionamentos nas ações.

\section{Proposta Metodológica}

Cinco parâmetros de comunicação entre os estudantes e o professor são a base de uma educação dialógica e problematizadora para David (2009). Segundo ela, no diálogo há pressupostos para estudos em interações: textos de sentimentos, respeito (afetividade); mensagens que demonstram igualdade de conhecimento (humildade); incentivo do professor aos estudantes (fé nos homens); contribuição no aprofundamento do conhecimento (esperança); reflexão crítica sobre o conteúdo (pensar crítico). Já Bassani (2009) trabalhou com seguintes parâmetros: relação do conteúdo (epistemológico); textos referentes às questões gerais tecnológicas (tecnológico); assuntos do contexto que vivenciou (social); expressões emotivas, saudações (afetivo).

Quadro 1 - Parâmetros relacionados às propostas de David e Bassani

\begin{tabular}{|c|c|c|c|c|c|c|}
\hline & $\mathbf{N}^{\mathbf{0}}$ & David & Bassani & David/Bassani & Dados Cruzados & A serem utilizadas \\
\hline 1 & amor & epistemológico & amor /afetivo & amor / afetivo & Amor / afetivo \\
\hline 2 & humildade & tecnológico & $\begin{array}{c}\text { amor / social- } \\
\text { afetivo }\end{array}$ & amor / social-afetivo & $\begin{array}{c}\text { pensar crítico / } \\
\text { epistemológico }\end{array}$ \\
\hline & 3 & fé nos homens & social & $\begin{array}{c}\text { pensar crítico / } \\
\text { epistemológico }\end{array}$ & $\begin{array}{c}\text { pensar crítico / } \\
\text { epistemológico }\end{array}$ & humildade \\
\hline & esperança & afetivo & ------ & epistemológico-social & fé nos homens \\
\hline & 5 & pensar crítico & epistemológico-social & ------ & humildade & esperança \\
\hline 6 & ------ & social-afetivo & ------ & fé nos homens & tecnológico \\
\hline 7 & ------- & ------- & ------ & tecnológico & social \\
\hline 8 & ------ & ------ & ----- & social & \\
\hline
\end{tabular}

Fonte: Elaboração própria a partir de Bassani (2009), David (2009) e Reis (2010) 
Nosso olhar está voltado para a demonstração de sete parâmetros, colocadas como categorias cruzadas a serem utilizadas nesta pesquisa, as quais são: 'amor / afetivo', 'pensar crítico / epistemológico', 'humildade', 'fé nos homens', 'esperança', 'tecnológico', 'social'. Damos início à classificação das postagens nos fóruns analisados, levando em consideração suas especificações.

\subsection{Procedimento Metodológico}

A presente pesquisa foi conduzida durante a realização do curso a distância Formação Continuada em Conselhos Escolares, do Programa Nacional de Fortalecimento dos Conselhos Escolares da Secretaria de Educação Básica (SEB) do Ministério da Educação (MEC), realizado pelo Instituto Universidade Virtual da Universidade Federal do Ceará. Coleta os dados em fóruns de discussão do AVA utilizados durante o curso. Neste artigo, analisaremos os dados do fórum do mesmo módulo, mas de anos diferentes, em 2011 e 2013, compostos de umas das maiores ocorrências em números de mensagens. Em 2011, 179 postagens e em 2013, 132.

\section{Análise do Experimento}

No Gráfico 1, analisamos a coluna ‘A serem utilizadas' do Quadro 1.

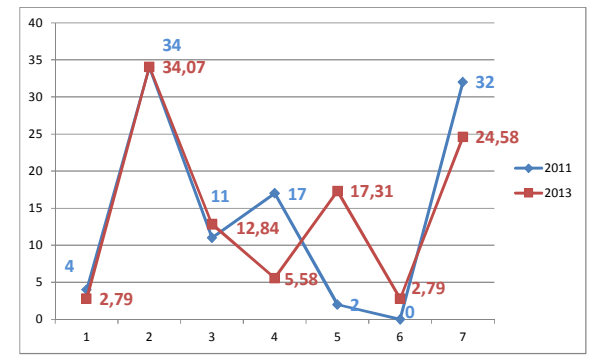

Gráfico 1. Este gráfico é cruzamento dos dados dos fóruns de 2011 e 2013.

No Gráfico 1, verificamos que os maiores percentuais são das categorias 'pensar crítico / epistemológico', de aproximadamente 34\% e 'social' de $32 \%$ e $24,58 \%$ em 2011 e 2013, respectivamente. Isto representa o perfil geral das turmas, que continuaram reflexivas ao mesmo passo que constroem o conhecimento com referência de ações sociais. Estes aspectos são ajudados pela proposta do fórum, que é 'Identificar resultados da função da escola relacionada à formação cidadã'.

As perguntas também induzem o percentual do parâmetro 'social', pois levam os sujeitos participantes a descreverem os contextos sociais locais onde vivenciam. São pontos importantes para que possamos localizar pistas de aprendizagens na sociedade.

Nos parâmetros 'fé nos homens' e 'esperança', identificamos diferenças consideráveis entre as turmas. Passamos a observar muitas contribuições de outras referências, logo, tornou o fórum bem fundamentado, ou seja, sinal do maior exercício da autonomia.

A categoria "humildade" se apresenta com 11\% em 2011 e 12,84\% em 2013. São números aproximados, em que a expressão de igualdade entre os sujeitos.

A nenhuma ou poucas postagens referentes à 'amor / afetivo' e 'tecnológico' indicam raros momentos de afetividade e o fórum não se tratar destas discussões. 


\section{A Análise Qualitativa da Aprendizagem}

Vejamos no Quadro 2 a amostragem qualitativo das postagens:

\section{Quadro 2 - Postagens em torno do Estudante 28 e suas interações}

\begin{tabular}{|c|c|c|}
\hline Interação & Postagem & Categoria \\
\hline \multirow{3}{*}{$\begin{array}{l}\text { Interação } \\
\text { individual } \\
\text { (sujeito } \\
\text { conteúdo) } \\
\text { para } \\
\text { Interação } \\
\text { Interindividual }\end{array}$} & $\begin{array}{l}\text { [Estudante 28]: Perceber a escola como um espaço para a construção do cidadão, isto é, } \\
\text { construir conhecimentos, atitudes e valores que tornem o estudante solidário, crítico, ético e } \\
\text { participativo, acredito ser o primeiro para a uma cidadania participativa, perpassando a gestão } \\
\text { democrática. E a escola tem feito feito isso em vários momentos, por exemplo quando organiza } \\
\text { os Conselhos Escolares e a comunidade escolar para participar e fazer valer os seus direitos e } \\
\text { cuprir deveres, bem como, a forma de escolha dos dirigentes. Estas são ações que trazem como } \\
\text { resultado a conquista de interesses coletivos e a construção de um Brasil para todos, livre das } \\
\text { injustiças e exclusões, que fazem tantas pessoas sofrer. Porém é importante ressaltar que esta } \\
\text { não é uma tarefa fácil, pois muitas dificuldades surgem e a escola vai tentando superá-las dia- } \\
\text { a-dia. }\end{array}$ & $\begin{array}{l}\text { pensar crítico / } \\
\text { epistemológico }\end{array}$ \\
\hline & $\begin{array}{l}\text { Re:/Re: - [Tutor]: Olá Aluno } 28 \text { ! } \\
\text { É isso mesmo. O ato da escola inserir o conselho escolar nas suas decisões é um incentivo e a } \\
\text { implantação de uma cultura de participação. Parabéns! } \\
\text { abs, }\end{array}$ & humildade \\
\hline & $\begin{array}{l}\text { Re:/Re: - [Estudante 36]: Concordo plenamente com você Aluno 28, a escola com certeza } \\
\text { vem contribuindo para o sucesso de cada cidadão. Parabéns pelas suas reflexões. }\end{array}$ & humildade \\
\hline
\end{tabular}

\section{Fonte: Elaboração própria a partir da pesquisa}

Inicialmente, o Quadro 2 reforça a nossa defesa da possibilidade de que os exemplos cotidianos podem levar a outros fatos diários, a afetividades, a consonância e a questionamentos. Isto fica claro nas experiências expressas, é respondido pelo Estudante 28, que por sua vez expõe uma mensagem relacionada à categoria 'humildade', porque demonstra sua concordância com o sujeito anterior.

A contribuição do Tutor neste processo de discussão ganha importância, pois instiga o Estudante 28 a refletir e continuar citando exemplos de acordo com a discussão, caracterizando um ato de 'fé nos homens'. Isto demonstra o gerenciamento e o acompanhamento da turma, isto é, a valorização da autonomia.

Ainda de acordo com o Quadro 2, há um fator importante, pois quem ocasiona uma interação interindividual é o Estudante 28, que provoca a participação do Tutor e o Estudante 36, que estão em consonância com a postagem anterior, logo, esses caracterizam a categoria 'humildade'. No entanto, o diferencial dessa vez é que o 28, em sua mensagem predomina o 'pensar crítico / epistemológico', porque fez uso de reflexão, comparação, justificativa em seus argumentos sobre o tema estudado.

Contudo, percebemos que tanto a quantidade quanto a qualidade das mensagens levam ao desempenho significativo do Estudante 28, pois estiveram presentes fatores de interação interindividual, reflexão, construção do conhecimento em torno de uma temática, portanto, foi uma demonstração de aprendizagem significativa.

\section{Considerações Finais}

É importante ficarmos atentos para o que muitos professores utilizam em sua ação no processo de aprendizagem, visto que o tempo é algo escasso para muitos perante a dimensão e desafios da educação brasileira, mesmo com direitos alcançados. E a situação se torna ainda mais desafiadora quando tratamos de Educação a Distância, pois as dificuldades começam desde a habilidade com a ferramenta computador, até as questões de cunho subjetivo, como as interações sociais. 
O momento que ocorre a construção do conhecimento mais significativo é demonstrado quando o parâmetro relacionado a reflexão crítica aparece, principalmente quando os estudantes são levados a pensar sobre seu contexto e suas experiências, a partir da exposição de seus relatos. Portanto, levando em consideração que houve também uma citação de vivências do cotidiano, identificamos que as turmas estudadas podem ser denominadas 'pensar crítico / epistemológico' e 'social'. Ainda na busca da identidade das turmas estudas, podemos verificar que, apesar de obtermos resultados de interação individual (sujeito - objeto), constatamos traços de interação interindividual (sujeito - conteúdo - sujeito).

O universo do trabalho investigativo possibilitou o aprofundamento de estudos dialógicos, trocas interacionistas, ainda que cientes que há muito ainda a desvendar, pois fizemos uso de apenas algumas possibilidades, como foram realizadas na interrelação dos parâmetros estudados. Como propostas futuras, podemos descobrir outros parâmetros de aprendizagem a partir de outros autores, assim como pode haver noutros estudos nos diversos campos da área de humanas, com objetivo de verificar comportamentos, papeis, atitudes, enfim, estudos sociológico, psicológico, filosófico, educacional, político, cultural, comunicacional. Também é válida a ideia de aplicação de questionários, entrevistas, mapeamentos das aprendizagens para identificar evidências da aprendizagem significativa.

A intenção é que o nosso estudo venha a ser mais uma referência para futuros trabalhos. Levando em consideração que estamos e somos interligados numa "teia", rede social em escala global, ainda que enfrentemos os desafios, sabemos que uma ação em lugar e momento adequados e estimulantes influenciar toda uma sociedade, levando-a a um permanente movimento de transformação.

\section{Referências}

BASSANI, P. B. S. (2009) Trocas interindividuais no fórum de discussão: um estudo sobre as comunidades de aprendizagem em espaços de educação à distância. Em: XX Simpósio Brasileiro de Informática na Educação. Florianópolis.

DAVID, P. B. (2009) Dialogicidade em práticas interativas da área de exatas. Em: XX Simpósio Brasileiro de Informática na Educação. Florianópolis.

FREIRE, P. (2006) Pedagogia do Oprimido. São Paulo: Paz \& Terra.

LÉVY, Pierre. (1999) Cibercultura. São Paulo: 34.

Moore, M. G. (1993). Theory of transactional distance. In: Keegan, D. Theorical Principles of Distance Education. Routledge: London. Notare, M. e Behar, P. A.

Peters, O. (2003). Didática do ensino a distância. São Leopoldo: Editora Unisinos. Reis, E. M. e Linhares, M. P.

PIAGET, Jean. (1983) Epistemologia Genética/Sabedoria e Ilusões da Filosofia/Problemas de Psicologia Genética. Em: Os pensadores.2 ed. São Paulo: Abril Cultural.

REIS, Ederclinger Melo. (2010) Uma análise da interação em fóruns de discussão de um ambiente virtual de aprendizagem. Em: XXI Simpósio Brasileiro de Informática na Educação. João Pessoa. 